\title{
Development of a Stator-Magnetless Linear Synchronous Motor for Sensorless Control
}

\author{
S. Makino, M. Kakihara, Y. Takase, M. Takaki, T. Shikayama, M. Ohto, T. Higuchi, Member, IEEE, \\ and T. Abe, Member, IEEE
}

\begin{abstract}
Sensorless control techniques that do not use a linear scale are desired for applications that require a long-stroke linear synchronous motor (LSM). This paper discusses the development of a stator-magnetless LSM (i.e., no magnet is mounted on the stator of the LSM) for sensorless control that includes a high-speed position estimation algorithm based on the magnetic hysteresis phenomenon. This paper presents a new structure of a flux-switching LSM that achieves a high saliency ratio using a cutout that results in magnetic saturation in the armature core. The effect of the sub-tooth on reducing the cogging thrust is also discussed. Furthermore, the analytical and experimental characteristics of inductance, thrust, cogging thrust, and sensorless drive control are discussed based on a prototype.
\end{abstract}

Index Terms - flux-switching; saliency; conveyance; long stroke; magnet-saving

\section{INTRODUCTION}

* ***** Linear synchronous motors (LSMs) are used in industrial machines for positioning and conveying equipment that require high speed and high precision. LSMs must detect the position of a mover to control its movement. Thus, a linear scale must be used throughout the length of the stator. However, maintaining precision and workability is a problem in the case of a long-stroke LSM with a linear scale.

Sensorless control is a technique for achieving motor control without using a linear scale and can be used to solve the aforementioned problem. Sensorless control is commonly used due to its many advantages, such as reduced cost and downsizing of the drive system, for both rotary and linear motors [1]-[3]. Moreover, previous studies have designed the structure of the motor to improve its sensorless control performance [4] [5].

Sensorless control techniques are classified according to the methods used to detect position [1], including the back electromotive force (EMF) detection method [6]-[10] and

Manuscript received 19, Dec, 2016; revised ****, 2017, accepted ****, 2017. Date of publication **** $20 * *$; date of current version ****, $20 * *$.

S. Makino, M. Kakihara, Y. Takase, M. Takaki, and T. Shikayama are with Yaskawa Electric Corporation, Kitakyushu, 803-8530, Japan (e-mail: Shogo.Makino@yaskawa.co.jp; $\quad$ Masanobu.Kakihara@yaskawa.co.jp; Yoshiyasu.Takase@yaskawa.co.jp; $\quad$ Mamoru.Takaki@yaskawa.co.jp; Toru.Sikayama@yaskawa.co.jp).

M. Ohto is with Yaskawa Motor Corporation, Kitakyushu, 805-0058, Japan (e-mail: Motomichi.ohto@yaskawa.co.jp).

T. Higuchi, and T. Abe are with Nagasaki University, Nagasaki, 852-8521, Japan (e-mail: thiguchi@nagasaki-u.ac.jp and abet@nagasaki-u.ac.jp). high-frequency signal injection method [12]-[15]. The back-EMF detection method uses voltage models [6] [7] or observers [8], which achieve good results in the mid- and high-speed regions. Although a method corresponding to low speed has been investigated [9]-[11], maintaining performance is difficult in the low-speed region, including zero speed or frequencies at which the back-EMF disappears. In contrast, the signal injection method can detect positions even at zero speed and low speeds due to the use of the magnetic saliency. By injecting a high-frequency signal, the saliency of the motor inductance is detected to estimate the mover position.

In the case of a long-stroke application, an LSM structure in which no permanent magnet is mounted on the stator, i.e., a stator-magnetless configuration, is appropriate because the usage of a permanent magnet does not increase with the stroke length. Generally, a magnet-saving motor reduces the usage of the permanent magnet. In this manner, the stator-magnetless LSM is cost effective and ensures improved workability [16]-[18]. A previous paper [16] suggested the use of a conveying system with a moving magnet (MM)-type LSM, with permanent magnets in the mover and winding coils in the stator that use sensorless position control. The system switches energizing coils according to the mover position to reduce the copper loss. Each of the energized sections contains an amplifier. However, additional coils and amplifiers are needed for long-stroke applications. In contrast, a moving coil (MC)-type LSM, which has winding coils in the mover and permanent magnets in the stator, might reduce the usage of winding and the amplifier. However, the strong magnetic attraction force causes a problem in terms of workability. In addition, the usage of a permanent magnet increases with the stroke length, thus increasing the cost of the system.

This paper discusses the development of a stator-magnetless LSM for sensorless control using the high-frequency signal injection method [19]. It focuses on a new structure of flux switching for the stator-magnetless LSM for sensorless control, which is based on previous studies [12]-[14]. The structure is designed to achieve a high saliency and reduce the cogging thrust using electromagnetic field analysis. Furthermore, the inductance, saliency ratio, thrust, cogging thrust, and sensorless drive control characteristics are demonstrated using a prototype. Moreover, the back-EMF detection method is not applied to reduce the complexity of the control-mode switching system. However, the high-frequency signal injection method can be combined with the back-EMF detection method in mid- and 


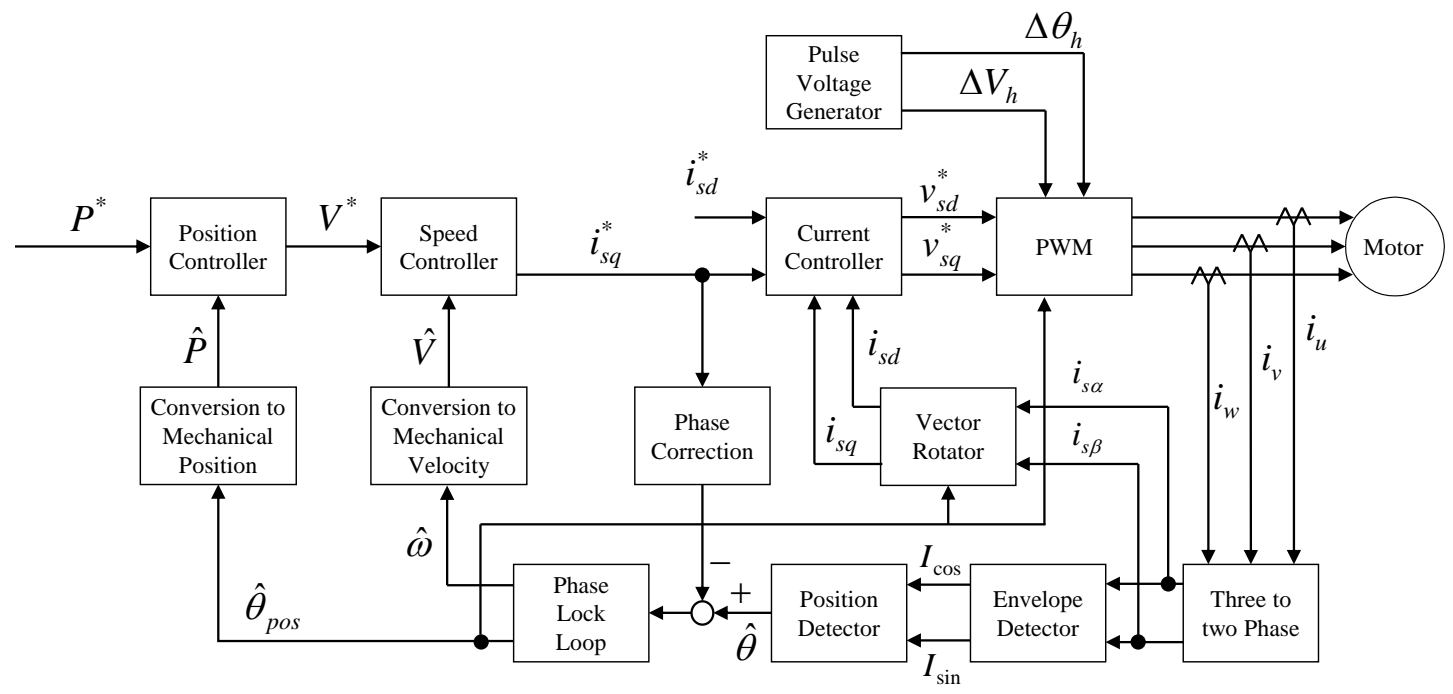

Fig. 1. Block diagram of the sensorless control.

high-speed operations, similar to previously demonstrated methods [20].

\section{STRUCTURE For SENSORLESS CONTROL}

\section{A. Sensorless Control}

This section describes the sensorless control technique using the stator-magnetless LSM. Fig. 1 shows a block diagram of the sensorless control in which the square-wave pulse voltage is injected along the d-axis to search for the rotor (i.e., mover) position. The switching period of the injected voltage $4 \Delta T_{s}$ is twice as long as that of the pulse width modulation (PWM) $2 \Delta T_{s}$, as shown in Fig. 2, where $\Delta T_{s}$ is the sampling time of position detection and current control. The injection angle $\Delta \theta_{h}$ is adjusted to inject the pulse voltage directly along the estimated d-axis. The response currents of the U-phase and V-phase, the waveforms of which are shown in Fig. 3 (a), are monitored by current sensors; then, alpha-phase and beta-phase current waveforms are obtained through the three-phase to two-phase transformation of the stationary reference frame. Fig. 3 (b) shows the waveforms of the two-phase currents. The envelope curves, which continuously connect the adjacent peak

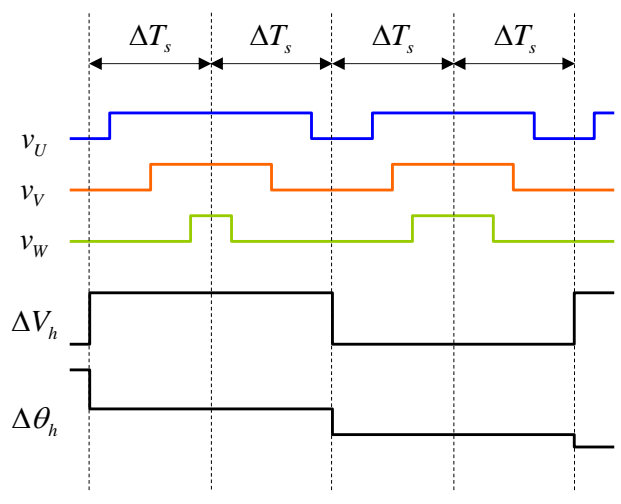

Fig. 2. Waveforms of the PWM voltage and injected voltage. points of each current waveform, indicate the mover position. The mover position is calculated directly as an arc-tangent value based on the assumptions that the alpha-phase envelope is a cosine curve and the beta-phase envelope is a sine curve. The mover position at the present time step is calculated as follows [12]-[14]:

$\hat{\theta}=\tan ^{-1}\left(\frac{I_{\text {sin }}}{I_{\cos }}\right)$

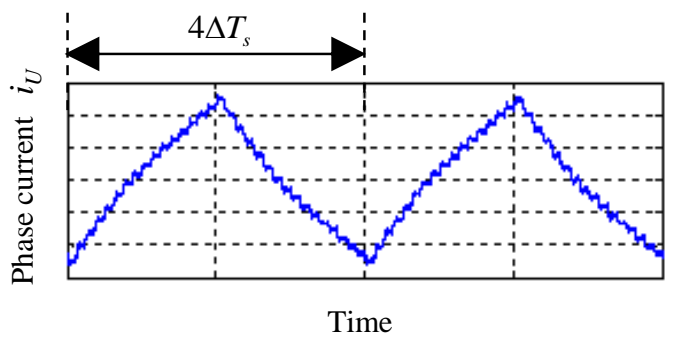

(a) Magnified waveform of the U-phase current
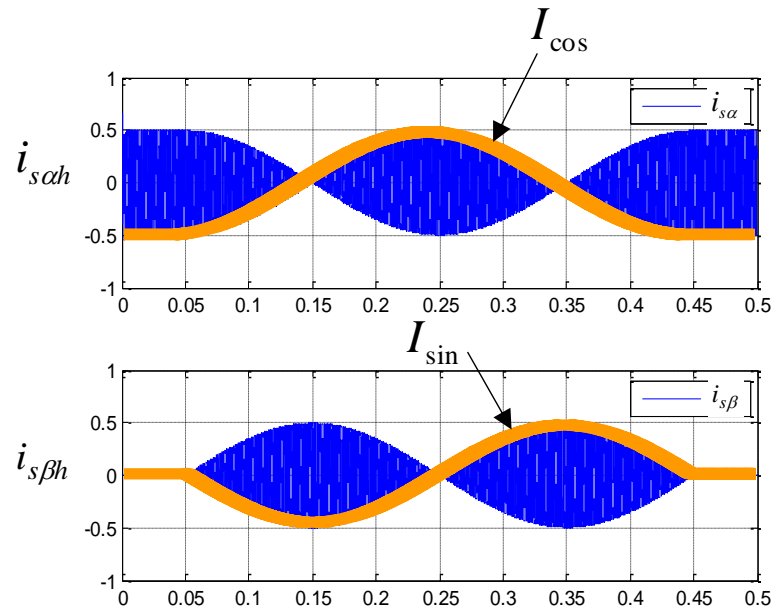

Time

(b) Overall waveform in the two-phase stationary reference frame

Fig. 3. Generated high-frequency current waveform. 
where $I_{c o s}$ is the alpha-phase envelope value based on the present and previous time step values of the alpha-phase current waveform and $I_{\text {sin }}$ is the beta-phase envelope value determined in a similar manner based on the beta-phase current waveform.

To improve the sensorless control performance, the estimation error between the estimated pole axis position and actual position must be reduced. The estimation error $\Delta \theta$ is linearized as follows [13]:

$$
\Delta \theta \propto-\frac{V_{h}\left|L_{d}-L_{q}\right|}{2 \omega_{h} L_{d} L_{q}}
$$

where $\omega_{h}$ and $V_{h}$ are the frequency and voltage of the injected signal, respectively, and $L_{d}$ and $L_{q}$ are the d- and q-axis inductances at high frequency, respectively.

To reduce the estimation error, the injected signal should be set at a low frequency or high voltage. Conversely, the motor characteristics consist of a small inductance along the $\mathrm{d}$ - and q-axes or a large difference between the d- and q-axes' with a high-frequency inductance, i.e., high saliency.

\section{B. Structure of the Stator-Magnetless LSM}

Fig. 4 shows two types of the stator-magnetless LSM structures. The term "stator-magnetless" indicates that no permanent magnet is mounted on the stator. Instead, the stator consists of only laminated electromagnetic steel sheets, i.e., the inductor. Fig. 4 (a) shows the MAGNAGAP linear motor (abbreviated as MGLM), which was described previously [17]. The mover is composed of an armature core, coils, and permanent magnets. Fig. 4 (b) shows the structure of the flux-switching linear motor (abbreviated as FSLM) [21] [22]. The mover consists of the armature core, coil, and permanent magnet. The parts are identical to those used in the MGLM.

Furthermore, the driving principles of both motors are nearly identical. When the mover is external, magnetic fluxes from permanent magnets are modulated by the inductor teeth, which generate alternating flux linkages to each phase winding and induce an EMF. In this way, the forces generated by the phase currents synchronized with the EMF are applied to the motor. The available combinations of magnet poles and inductor teeth

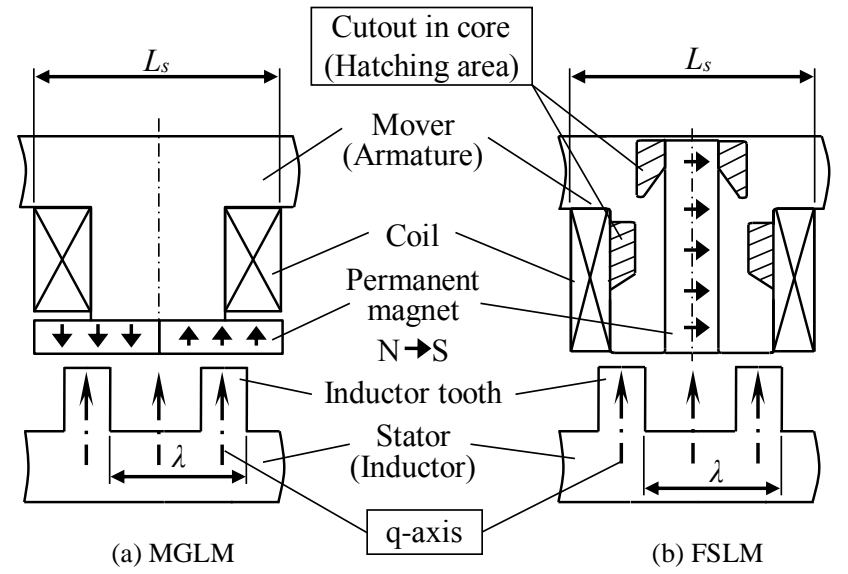

Fig. 4. Structure of the stator-magnetless LSM (q-axis). have been described in previous studies [17] [22]. The placement of the permanent magnet differs between the MGLM and the FSLM. The permanent magnets in the MGLM are mounted on the surface of the armature core, whereas the permanent magnet in the FSLM is installed inside the armature core.

To achieve high saliency characteristics, the magnetic gap should be small, and the amplitude of the magnetic resistance variation should be high. The magnetic gap in an MGLM is relatively large because a permanent magnet is located between the armature core and inductor teeth. Thus, the magnetic resistance is relatively insensitive to changes in the mover position. The saliency is also small. In contrast, the magnetic gap in an FSLM is small because the armature core, including the permanent magnet, faces the inductor teeth. Thus, the magnetic resistance variation and saliency are greater than that of an MGLM.

\section{Cutout for High Saliency}

Fig. 5 shows the magnetic flux density distribution and magnetic flux line. These results are based on a 2D finite element method (FEM) analysis of a basic model, which is similar to that shown in Fig. 4 (b) expect a sub-tooth, i.e. that of the non-sub-tooth.

The $d$-axis is defined as a mover position of 0 degrees in the electrical angle, where the flux linkage is at a maximum, and the d-axis inductance is at a minimum. Moreover, the q-axis shifts from the d-axis by an electrical angle of 90 degrees. Thus, the q-axis inductance is also maximized.

The cutout in the armature core is designed to generate magnetic saturation and increase the saliency. In the d-axis position, the armature core around the cutout and a part of the teeth reach magnetic saturation. The magnetic saturation prevents the magnetic flux of coils from flowing through the teeth. The inductance of the coil depends on the magnetic saturation, which varies with the relative position between the mover and stator. Thus, the inductance with the cutout is less than that without the cutout. In contrast, the magnetic saturation is relieved in the q-axis position. The influence of the magnetic saturation by the cutout becomes small; thus, the inductance is nearly identical to the inductance without the cutout.

Therefore, due to the cutout, the variation of the inductance between the d-and q-axes is large, i.e., the saliency becomes

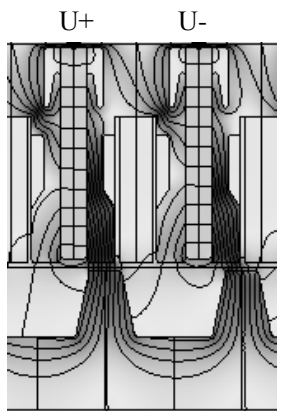

(a) d-axis

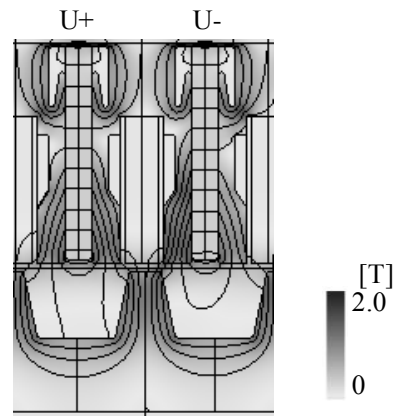

(b) q-axis
Fig. 5. Magnetic flux density distribution and line. 


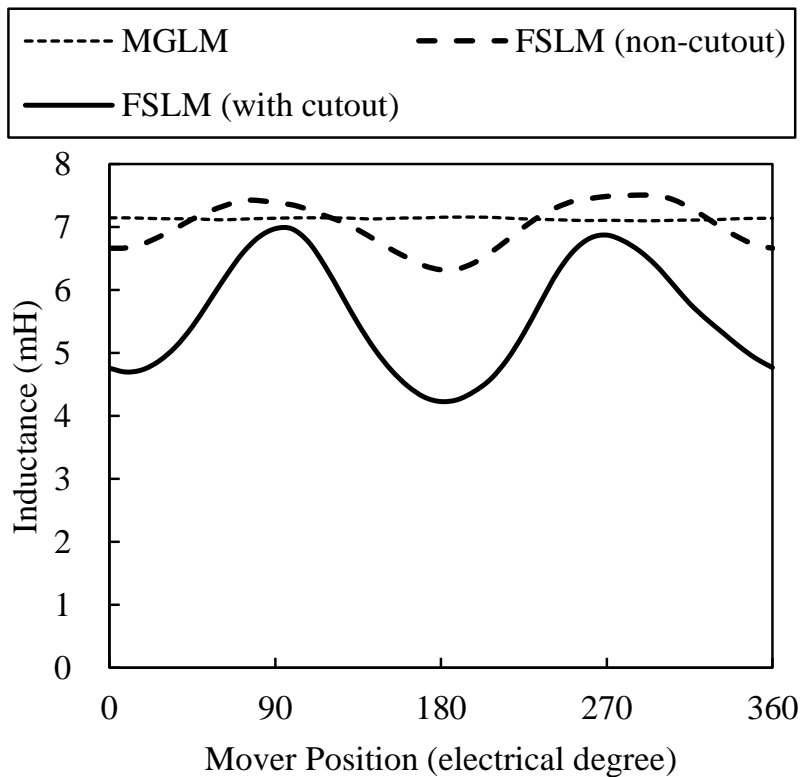

Fig. 6. Analysis of inductance characteristics ( $L u, 100$ coil turns).

high.

Fig. 6 shows the calculated results for the inductance characteristics at no load obtained by a 2D FEM analysis of one-phase inductance. The FEM analysis uses the basic model, in which the number of turns per coil is equal, and the size of the permanent magnets and the core in the mover are similar.

The waveform of the MGLM is nearly flat because the magnetic resistance variation is low. The saliency ratio of the FSLM is greater than that of the MGLM (1.10 and 1.01, respectively). Moreover, in the d-axis position, an FSLM with a cutout results in lower inductance than an FSLM without a cutout. In the q-axis position, the inductances of an FSLM with and without a cutout are approximately equal. Thus, the saliency becomes high.

As a result, the saliency ratio of an FSLM with a cutout is 1.40 , which is greater than that of an FSLM without a cutout.

\section{Sub-tooth for Cogging Thrust Reduction}

In an LSM with a permanent magnet, the cogging thrust occurs due to the unbalanced magnetic circuit at the end of the mover, i.e., the end effect. The cogging thrust causes force ripple, thereby producing vibration and noise. Previous papers [23]-[26] have suggested optimizing the stator length and supplement tooth to cancel the cogging thrust. In particular, in the stator-magnetless LSM, a permanent magnet is added to the supplement tooth to increase the influence of the magnetic circuit because the stator does not include a permanent magnet.

In the supplement tooth and permanent magnet on both ends of the mover, called the sub-tooth, shown in the dashed range of Fig. 7, the shape, dimensions, and air gap are designed to reduce the cogging thrust using the electromagnetic field analysis.

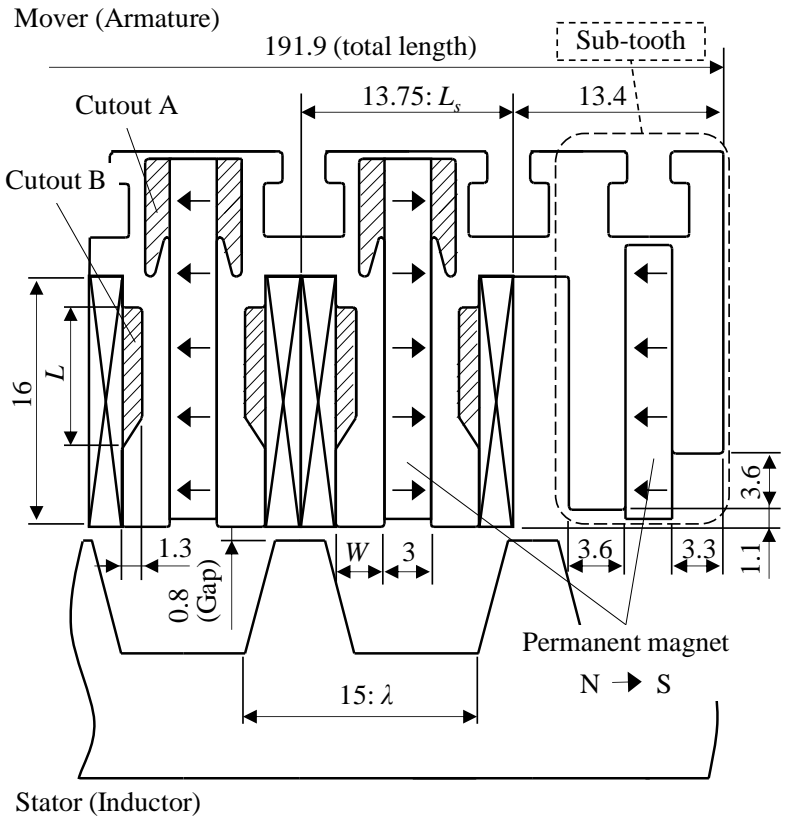

Fig. 7. Proposed schematic diagram of a FSLM. The units are mm. Hatched areas indicate the cutout in the core. The length of the laminate in the laminating direction is $50 \mathrm{~mm}$.

\section{DESIGN CONSIDERATIONS For FSLMs}

\section{A. Analytical Model}

Fig. 7 shows the proposed schematic diagram of the FSLM. Permanent magnets are installed inside the armature core, and the coils are wound around the teeth of the armature core.

The cutout in the back yoke side, adjacent to the permanent magnet, is defined as cutout A and primarily blocks magnetic flux, similar to a flux barrier. The cutout in the tooth adjacent to the slots is defined as cutout $\mathrm{B}$; this cutout generates magnetic flux saturation for high saliency.

The shape of cutout $\mathrm{A}$ is designed to produce high thrust. The shape of cutout B is optimized to increase saliency. Thus, the tooth width $W$ of the armature core and the cutout length $L$ are defined as design parameters.

\section{B. High Saliency}

Fig. 8 shows the calculated saliency ratio and back-EMF obtained by FEM analysis. The back-EMF is the amplitude of a fundamental wave in a speed of $1 \mathrm{~m} / \mathrm{s}$ produced by an outside drive.

Fig. 8 (a) shows the result when the armature core does not have a cutout, i.e., when $L$ is zero. Both characteristics depend on the value of $W$. The back-EMF depends on the total magnetic flux. When $W$ is small, the entire tooth generates magnetic flux saturation. Thus, a thinner armature core leads to a higher saliency ratio and lower back-EMF. The cutout length $L$ is set to $3.1 \mathrm{~mm}$, the saliency ratio is 1.16 , and the back-EMF is $18.8 \mathrm{~V}$.

The cutout depth influences the saliency ratio and EMF in the same manner as the tooth width $W$. When $W$ is constant, a thicker cutout narrows the path of the magnetic flux and leads to magnetic saturation of the core. Thus, a thicker cutout leads 
to a higher saliency ratio and lower back-EMF, which is the opposite of the trend shown in Fig. 8 (a). The cutout depth is set to $1.3 \mathrm{~mm}$, which is approximately $40 \%$ of the tooth width $W$.

Fig. 8 (b) shows the results when $W$ is $3.1 \mathrm{~mm}$. Both characteristics depend on the value of $L$. When $L$ is large, the cutout in the tooth generates magnetic flux saturation, particularly along the d-axis, as illustrated in section II-C. Thus, the saliency ratio is greater than that of the non-cutout model, i.e., the saliency ratio is 1.33 , and is maximized when $L$ is between 9 and $10 \mathrm{~mm}$. The tooth width of the armature core $W$ is set to $9.1 \mathrm{~mm}$, inside the optimized range.

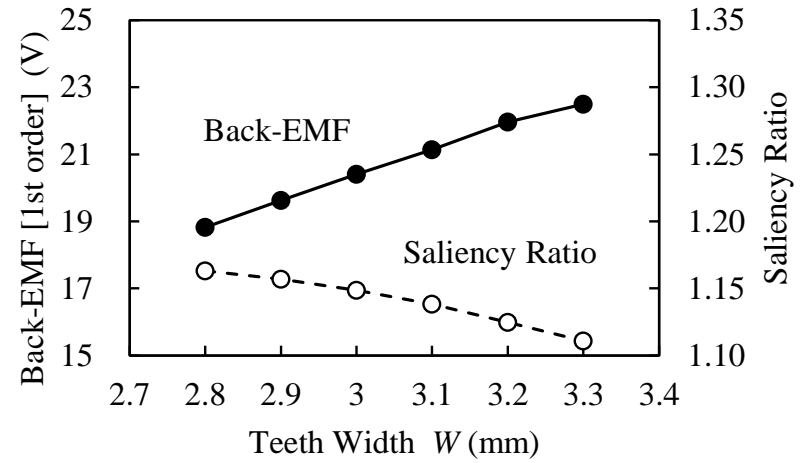

(a) Results for $W$ when $L$ is zero.

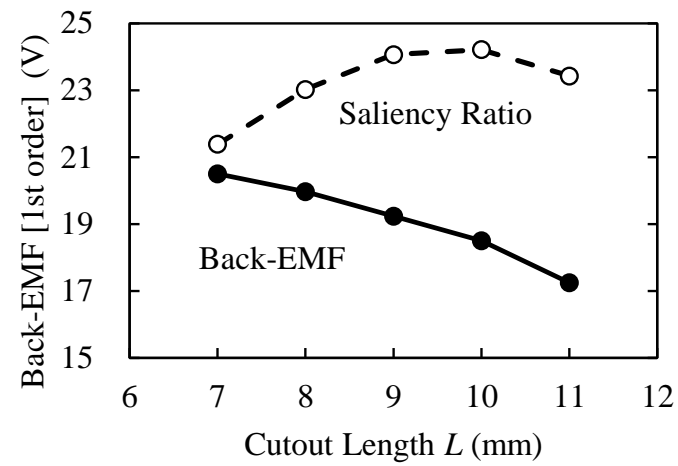

(b) Results for $L$ when $W$ is $3.1 \mathrm{~mm}$.

Fig. 8. Analysis of results for the saliency ratio and back-EMF.

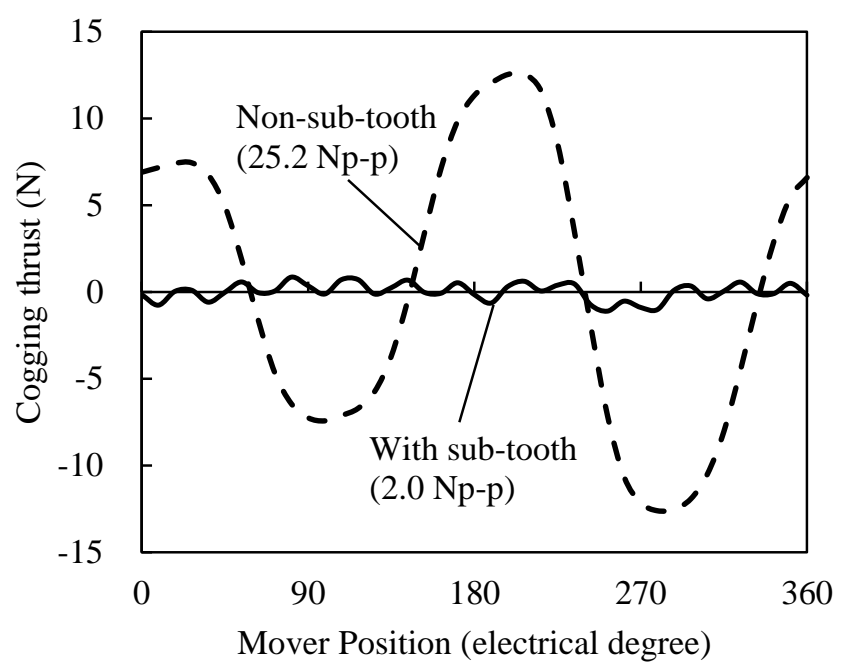

Fig. 9. Analysis of cogging thrust characteristics.
These results illustrate that the cutout has a significant effect as the motor achieves a high saliency even if the back-EMF voltage is the same.

\section{Reducing Cogging Thrust}

Fig. 9 shows the results of the cogging thrust characteristics obtained by FEM analysis. The cogging thrust for the model without a sub-tooth exhibits a large value of the second-order harmonic component. The sub-tooth shape and dimensions were designed using electromagnetic field analysis.

As a result, the case in which a sub-tooth is included results in a small cogging thrust that has been significantly reduced from 25.2 Np-p (peak-to-peak) to 2.0 Np-p.

\section{Improving the Waveform of the Back-EMF}

Fig. 10 shows the calculated results of the back-EMF waveform and the amplitude ratios of the harmonics components in the overall waveforms of the back-EMF

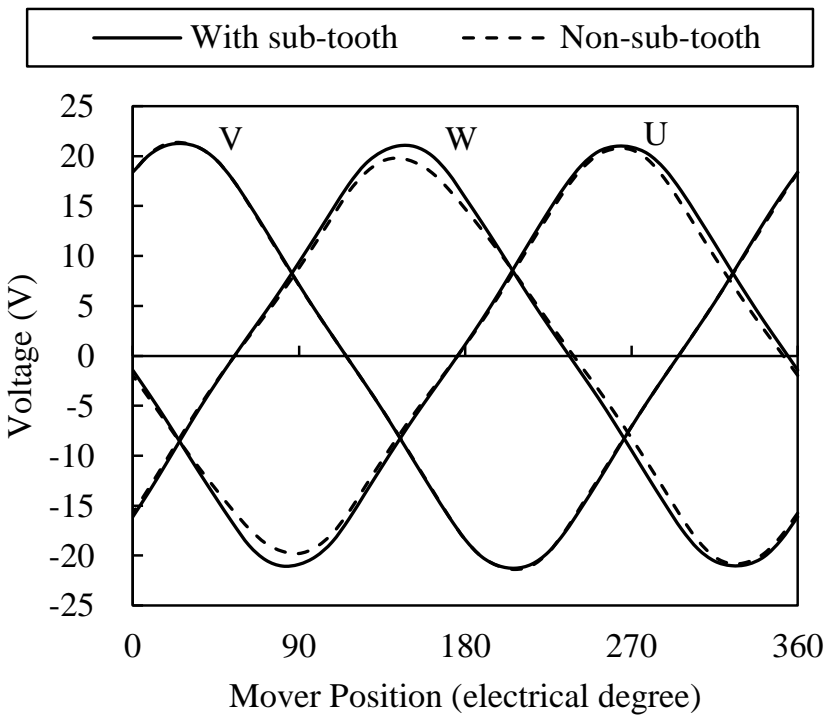

(a) Back-EMF waveform

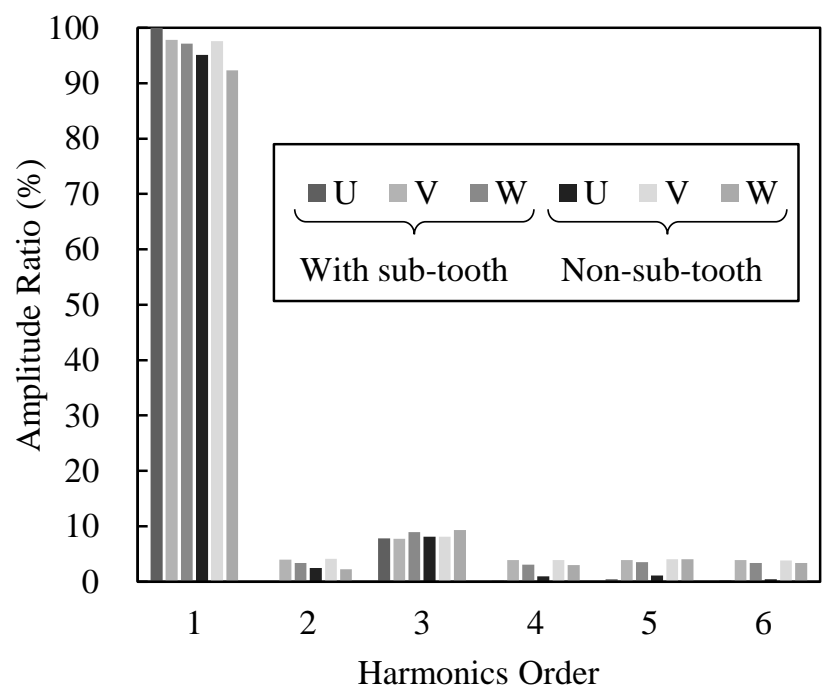

(b) Amplitude ratio in the overall waveform.

Fig. 10. Analysis of back-EMF characteristics. 
obtained by FEM analysis at $1 \mathrm{~m} / \mathrm{s}$ via an outside drive. The analysis model with a sub-tooth is shown in Fig. 7. In Fig. 10 (b), the U-phase amplitude ratio with a sub-tooth is taken as the standard (i.e., 100\%).

The non-uniform waveform of the back-EMF also causes a force ripple. The back-EMF waveform is generally brought closer to a sinusoidal wave by adjusting motor design parameters such as the width of the teeth and permanent magnets in the mover. Specifically, heterogeneity of the path of the magnetic flux is produced by the edge effect with the LSM. However, the waveform with a sub-tooth model is improved and exhibits an approximately sine-curved shape, particularly for the U- and W-phase waveforms, which are located at both ends of the mover. The difference in amplitude with the sub-tooth is small, with a value of less than $3 \%$, which is half of that of the non-sub-tooth waveform. The non-uniform waveform of the back-EMF causes a force ripple. Additionally, the fundamental component of the waveform with a sub-tooth is greater than that of the non-sub-tooth waveform.

As a result, the case in which a sub-tooth is used also results in an approximately sine-curved shape, which reduces the thrust pulsation.

\section{Characteristics Of the Prototype}

\section{A. Specifications}

Fig. 11 shows the FSLM prototype. In the mover, the permanent magnet is installed inside the armature core. The plate is located on the back yoke of the armature core for structural support. The mover is molded with resin to improve its mechanical and electrical reliability. Moreover, the stator consists of only a laminated electromagnetic steel sheet, i.e., the inductor.

Table 1 shows the specifications of the FSLM prototype. The combination of the FSLM contains 12 poles in the mover and 11 teeth in the stator, which produces a smooth (low-harmonic) waveform of inductance for the sensorless control and a high winding factor, resulting in a compact linear motor [21]. The driving frequency is $200 \mathrm{~Hz}$ at $3.0 \mathrm{~m} / \mathrm{s}$. The induced voltage constant, which is the average of three phases, is $98 \%$ of the

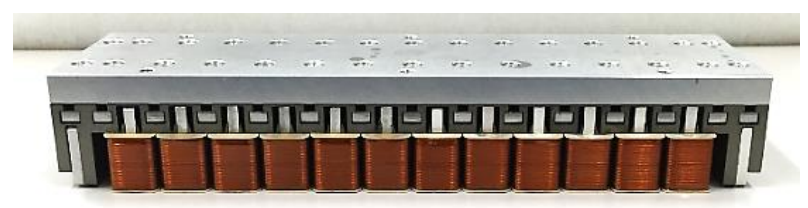

(a) Mover (before molding)

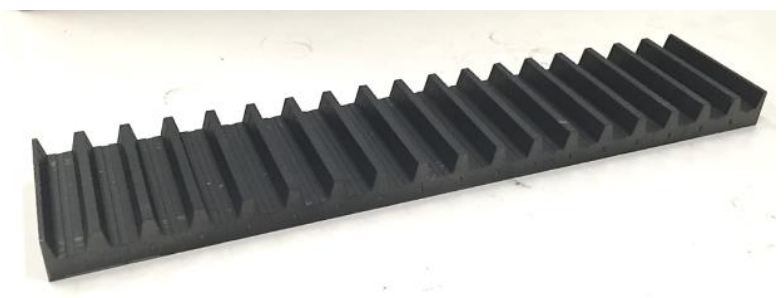

(b) Stator (painted)
TABLE I. SPECIFICATIONS OF THE FSLM PROTOTYPE

\begin{tabular}{|l|l|}
\hline \multicolumn{1}{|c|}{ Item } & Value (unit) \\
\hline Maximum thrust & $150(\mathrm{~N})$ \\
\hline Maximum speed & $3.0(\mathrm{~m} / \mathrm{s})$ \\
\hline Resistance / phase & $2.67(\Omega)$ \\
\hline Inductance / phase (1kHz) & $\begin{array}{l}\mathrm{Lq}: 7.9(\mathrm{mH}) \\
\mathrm{Ld}: 6.1(\mathrm{mH})\end{array}$ \\
\hline Induced voltage constant & $12.9(\mathrm{~V} / \mathrm{m} / \mathrm{s})$ \\
\hline $\begin{array}{l}\text { Number of slots in the mover } \\
\text { (coil and permanent magnet) }\end{array}$ & 12 \\
\hline Number of teeth in the stator & 11 \\
\hline Number of turns per coil & $59($ turns $)$ \\
\hline Magnetic flux density & $1.27(\mathrm{~T})$ \\
\hline
\end{tabular}

calculated result.

\section{B. Inductance Characteristics}

Fig. 12 shows the measured inductance results. $L u-v, L v-w$, and $L w-u$ are the inductances between the lines of each phase. The inductances are measured with an LCR meter with excitation conditions of $1 \mathrm{kHz}$ and $10 \mathrm{~mA}$.

The inductance between the $\mathrm{U}$ and $\mathrm{W}$ phase is affected by the end effect of the leakage flux. Due to the modification in the design by adding the sub-tooth as shown in Fig. 7, it can be observed from the measured data shown in Fig. 12 that the phase inductance has an approximately sine-wave shape. The average saliency ratio is 1.30 .

The results confirm that the motor has high saliency characteristics.

Fig. 13 shows the measured inductance characteristics at each rated load condition. The mover is fixed at an electrical angle of 0 degrees. The rated currents shown in the bottom of Fig. 13 are applied. The test conditions include an injection frequency of $1 \mathrm{kHz}$ and an injection voltage of $60 \mathrm{~V}$. The high-frequency inductance $L_{\theta}$ is given in reference to the impedance relationship as follows:

$$
\begin{aligned}
& |Z|=V_{m} / I_{m}=\sqrt{R^{2}+\left(2 \pi f_{m} L_{\theta}\right)^{2}} \\
& L_{\theta} \approx V_{m} / 2 \pi f_{m} I_{m}
\end{aligned}
$$

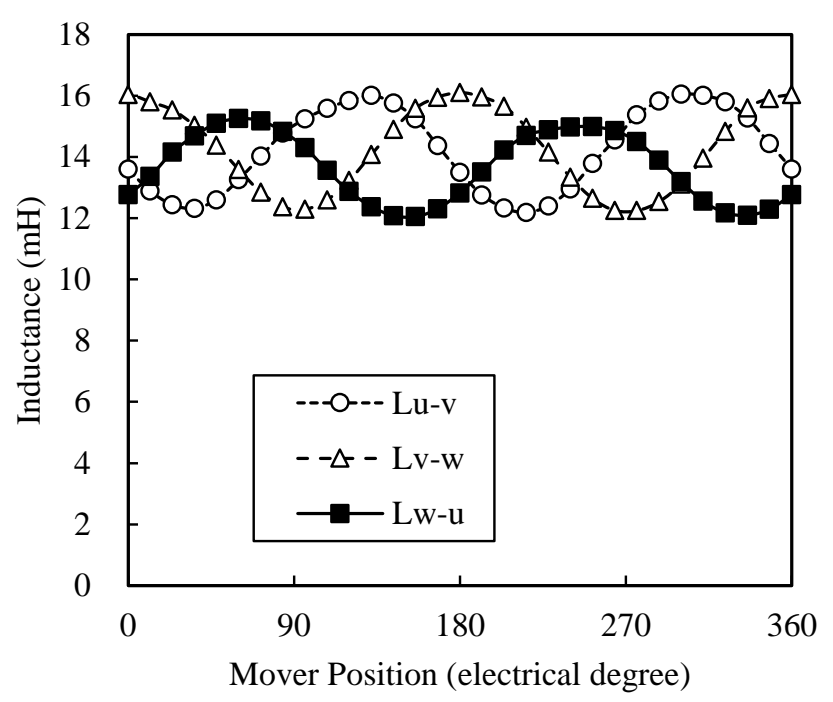

Fig. 12. Measured inductance characteristics.

Fig. 11. FSLM prototype. 


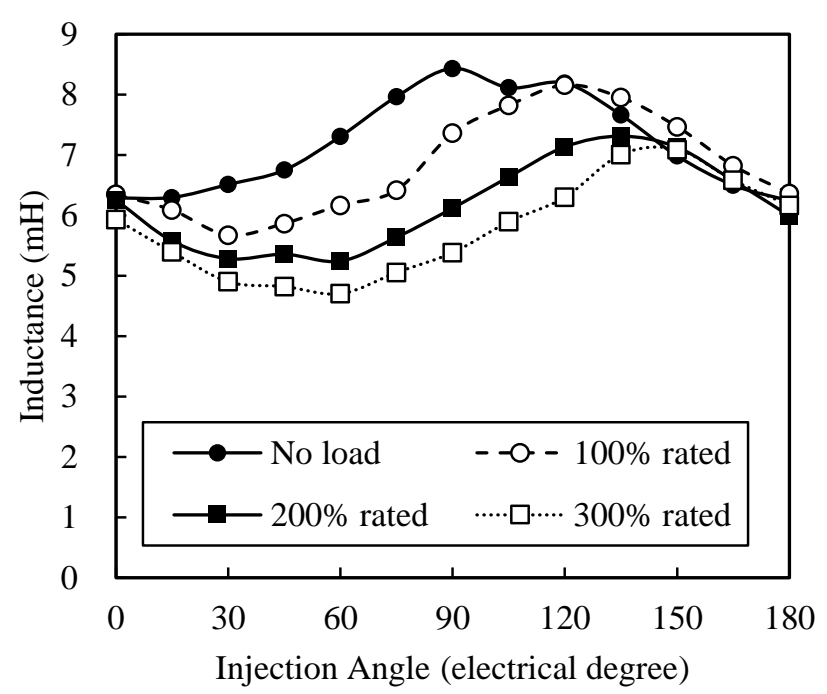

Fig. 13. Measured inductance characteristics at each rated load condition.

where $V_{m}$ and $I_{m}$ are the measured high-frequency voltage and current, respectively, and $f_{m}$ is the frequency of the injection voltage, i.e., $1 \mathrm{kHz}$. The resistance is much smaller than the inductance and can be considered negligible. The injection angle varies from an electrical angle of 0 to 180 degrees.

The saliency ratio remains high even in the case of a high rated load. As a result, high saliency is achieved over all load conditions. Nevertheless, the injection angle at minimum inductance deviates from 0 degrees when a large load current is applied to the motor because of the change in the path of the magnetic flux by the magnetic saturation. This condition leads to the phase estimation error associated with sensorless control [27].

Therefore, phase correction, which depends on the load current, is implemented for the phase angle based on the load condition to ensure the stability of the drive. The value of the phase correction is calculated using the current command $i_{s q}$ and an approximation of the phase correction. The phase correction tends to reduce the phase estimation error when the speed increases or decreases due to changes in the torque used for speed and positioning control. The phase estimation error in the actual drive is slightly different from the measured results, shown in Fig.13, because of the dependence on the control condition. Hence, an approximation of the phase correction which was coordinated at 24 electrical degrees per $300 \%$ rated load by the actual drive, was applied.

Fig. 14 shows the measured effect of the phase correction for various rated load currents. In the fixed mover, the estimation errors shown in Fig.14 (a) between the estimated position and the actual position, and the thrust command error shown in Fig.14 (b) between the thrust command calculated from the current command and the fixed force, i.e., the actual thrust, are measured. The thrust command error is the decrease due to the reduced estimation error.

For the non-correction condition, the drive becomes uncontrollable with a load greater than $\pm 200 \%$ of the rated load current. With phase correction, the estimation error and thrust

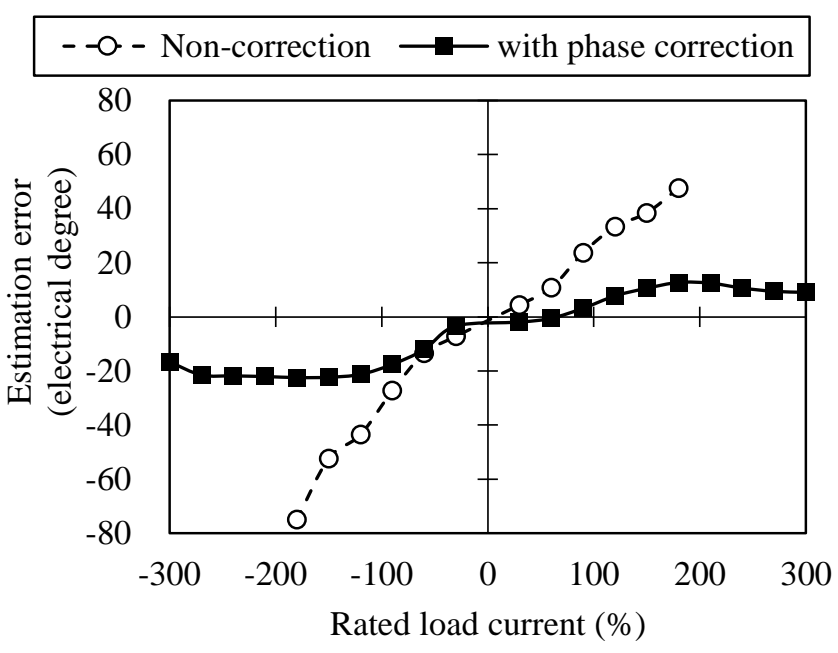

(a) Estimation error.

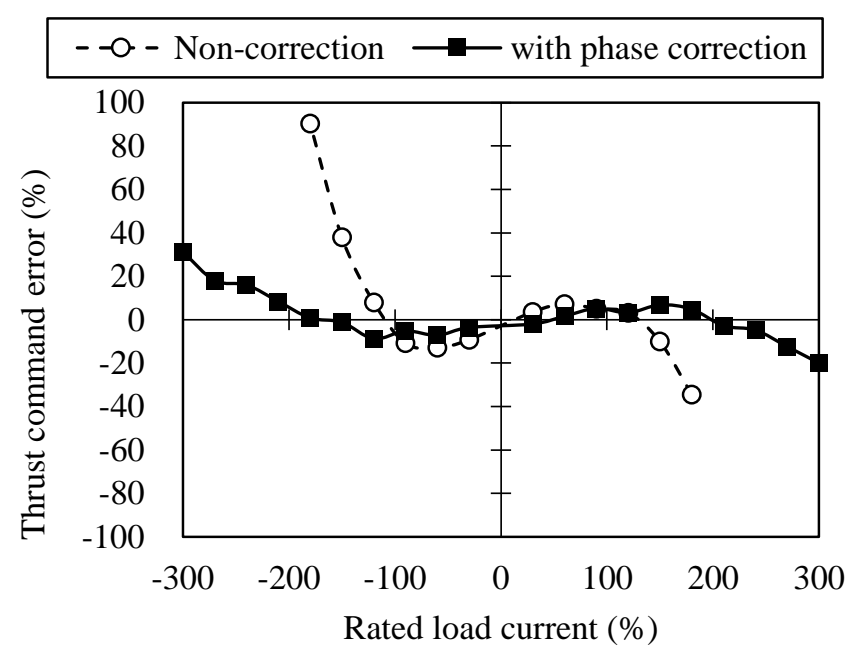

(b) Thrust command error.

Fig. 14. Measured effect of the phase correction.

command error can be improved, and the thrust closely corresponds to the thrust command. Thus, the phase correction is effective to reduce the estimation error.

\section{Thrust Characteristics}

Fig. 15 shows the measured thrust characteristics and the FEM analysis results. The thrust is measured using a dynamometer (model 9257B, manufactured by Kistler). The mover is fixed along the q-axis, and its values are obtained under the same conditions as in the FEM analysis.

The measured results are slightly lower than the FEM analysis results; the linearity of the thrust is $91 \%$ at $155 \mathrm{~N}$. Thus, the maximum thrust satisfies the relevant specifications.

\section{Cogging Thrust Characteristics}

Fig. 16 shows the measured cogging thrust characteristics and the FEM analysis results.

The measured cogging thrust is $5.3 \mathrm{~Np}-\mathrm{p}$, and the ratio to the maximum thrust is $3.5 \%$, which indicates the potential for practical use. Thus, the effect of the sub-tooth on reducing the cogging thrust is large relative to that of the non-sub-tooth 


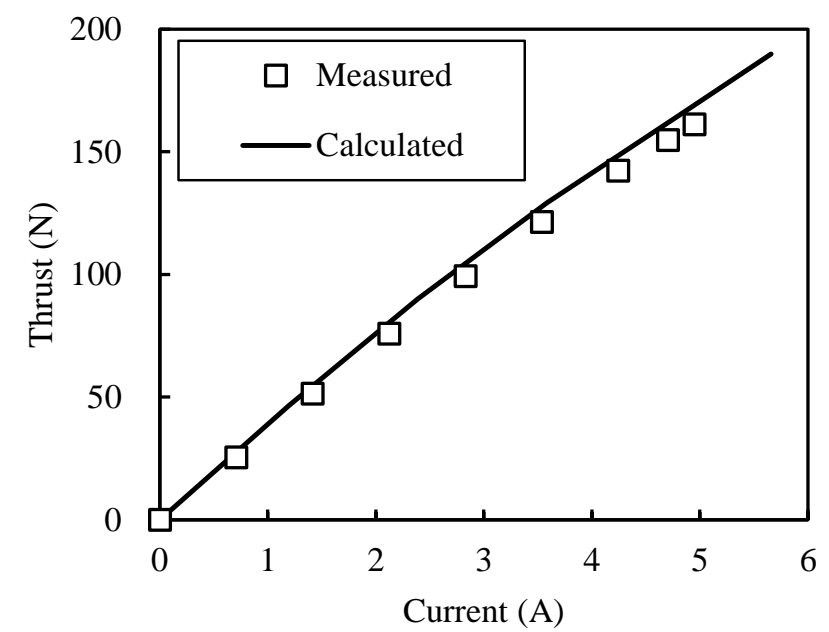

Fig. 15. Measured thrust characteristics.

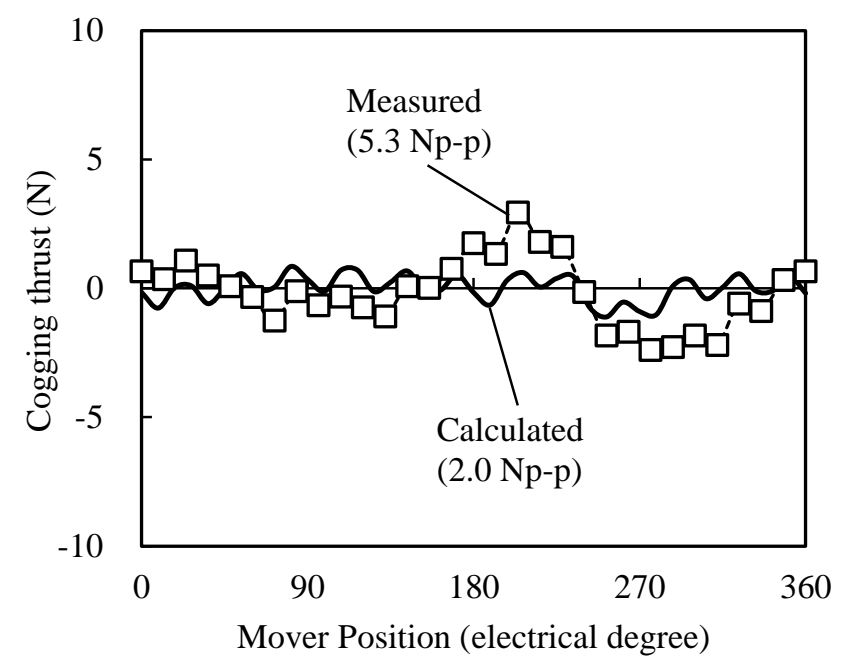

Fig. 16. Cogging thrust characteristics.

condition, as shown in Fig. 9.

\section{E. Sensorless Control Characteristics}

Fig. 17 shows a linear slider driven by sensorless control based on the high-frequency signal injection method. The linear slider has a slide table, which is supported by two linear motion bearings. The mover is attached under the slide table. The stator is located at the base along the linear motion bearing. A linear

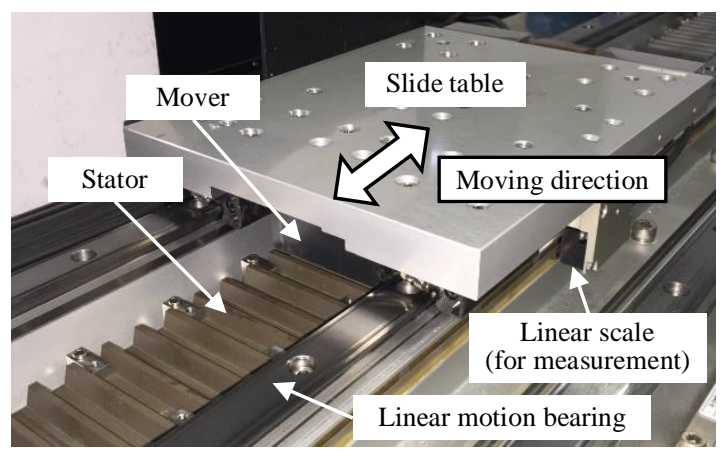

Fig. 17. Linear slider used for driving motion. scale for measuring the position is mounted on the side of the linear slider. The driver uses an SGD7S SERVOPACK (Yaskawa Electric Corporation) with sensorless control software. The test conditions include an injection frequency of approximately $10 \mathrm{kHz}$, an injection voltage of $80 \mathrm{~V}$, and a load (including the mover and the slide table) of $5.7 \mathrm{~kg}$.

Fig. 18 shows the measured moving speed characteristics using sensorless control. Fig. 18 (a) shows the estimated speed. Fig. 18 (b) shows the speed command and the measured speed of the linear scale. The stroke length is $1.3 \mathrm{~m}$, and the maximum speed is $3.0 \mathrm{~m} / \mathrm{s}$.

Although the estimated speed varies slightly, the measured speed is nearly consistent with the speed command. These results illustrate that speed control of the prototype can be achieved with sensorless control. The estimated speed variation causes not only the estimated error shown in (2) and the thrust command error shown in Fig. 14 but also the high gain setting that depends on the phase lock loop (PLL). A low-pass filter is located in the PLL, and variation of the estimated speed signal is reduced due to the feedback signal for the controllers, as shown in Fig. 1. To reduce the variation of the estimated speed, the drive control can be adjusted using the PLL.

Fig. 19 shows the experimental results for the speed control dynamics. When the speed command is increased from 0 to 0.3 $\mathrm{m} / \mathrm{s}$, the settling time $t_{\text {set }}$ is approximately $19 \mathrm{~ms}$. The settling time $t_{\text {set }}$ is defined as the time interval between the time when

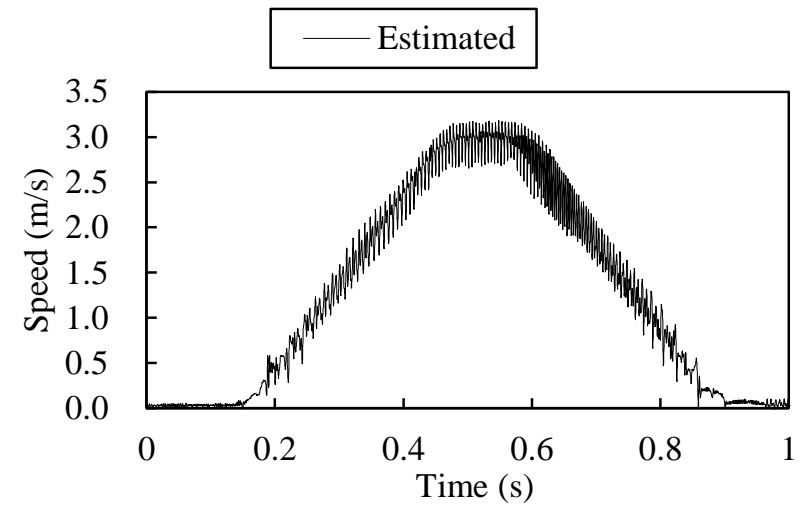

(a) Estimated speed.

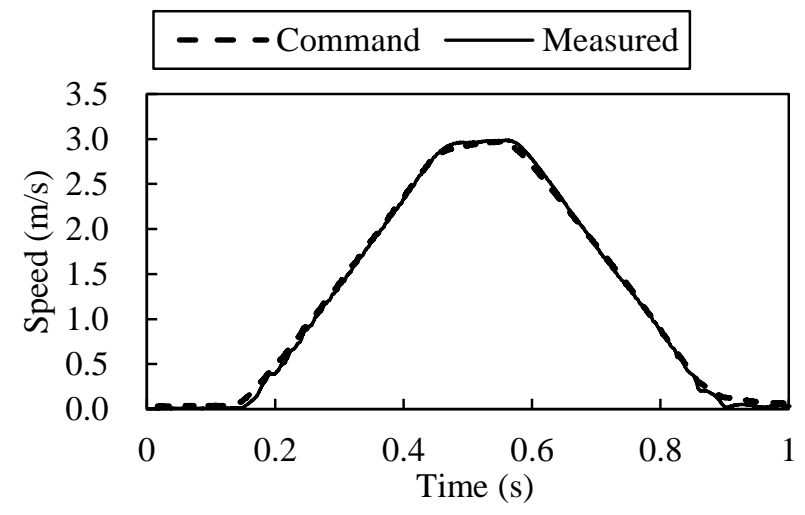

(b) Speed command and measured speed.

Fig. 18. Moving speed characteristics achieved by sensorless control. 


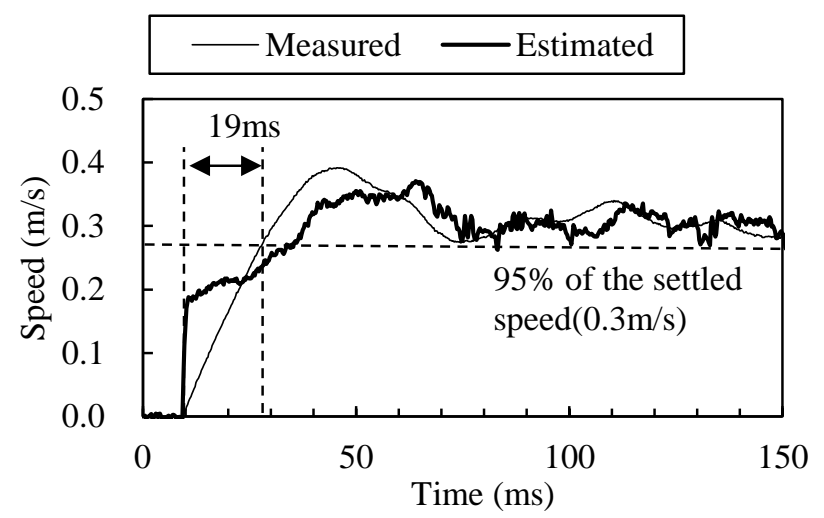

Fig. 19. Speed control dynamics characteristics.

the actual speed begins to increase and the time when the actual speed reaches $95 \%$ of the speed command value. Assuming that the control system is approximately a first-order system, the typical speed control bandwidth $f_{\text {typ }}$ is defined as

$f_{t y p}=\frac{1}{2 \pi} \frac{1}{t_{\text {set }} / 3}=\frac{3}{2 \pi t_{\text {set }}}$

Using this definition, the typical speed control bandwidth $f_{\text {typ }}$ of this drive system is $25 \mathrm{~Hz}$. Thus, servo drive control of the prototype is achieved using sensorless control.

\section{CONCLUSIONS}

This paper discussed the development of a stator-magnetless LSM for sensorless control using the high-frequency signal injection method. A new structure of flux switching of the stator-magnetless LSM for sensorless control was proposed. The cutout and the sub-tooth were designed to achieve high saliency and reduce cogging thrust. Furthermore, the characteristics of inductance, saliency ratio, thrust, cogging thrust, and sensorless drive control were confirmed using a prototype. The practical benefits of this system include reduced cost and downsizing of the drive system in relatively long-stroke applications because the application of sensorless control to the stator-magnetless LSM simplifies the stator configuration.

\section{REFERENCES}

[1] Sul, and S. Kim, "Sensorless control of ipmsm: Past, present, and future," IEEJ J. Ind. Appl., vol. 1, no. 1, pp. 15-23, Jul. 2012.

[2] F. Cupertino, P. Giangrande, M. Scaringi, S. Stasi, and L. Salvatore, "Sensorless control of linear tubular permanent magnet synchronous motors using pulsating signal injection," in Conf. Rec. IEEE IAS Annu. Meeting, Oct. 2008. pp. 1-8.

[3] M. A. M. Cheema, and J. E. Fletcher, "Sensorless vector control of linear permanent magnet synchronous motor," in Conf. Rec. ECCE Asia, Jun. 2013, pp. 1098-1104.

[4] S. Murakami, M. Ohto, M. Hisatsune, T. Shiota, and K. Ide, "Encoderless motor design for servo drive applications," in Conf. Rec. ICPE and ECCE Asia, May-Jun. 2011, pp. 2196-2203.

[5] Y. C. Kwon, S. K. Sul, N. A. Baloch, S. Morimoto, and M. Ohto, "Design, Modeling, and Control of an IPMSM With an Asymmetric Rotor and
Search Coils for Absolute Position Sensorless Drive,", IEEE Trans. Ind. Appl., vol. 52, no. 5, pp. 3839-3850, Jun. 2016.

[6] S. Morimoto, K. Kawamoto, M. Sanada, and Y. Takeda, "Sensorless control strategy for salient-pole PMSM based on extended EMF in rotating reference frame," IEEE Trans. Ind. Appl., vol. 38, no. 4, pp. 1054-1061, Aug. 2002.

[7] M. Tsuji, K. Kojima, K., Mangindaan, D. Akafuji, and S. I. Hamasaki, "Stability study of a permanent magnet synchronous motor sensorless vector control system based on extended EMF model," IEEJ J. Ind. Appl., vol. 1, no. 3, pp. 148-154, Nov. 2012.

[8] S. C. Yang, and R. D. Lorenz, "Surface permanent-magnet machine self-sensing at zero and low speeds using improved observer for position, velocity, and disturbance torque estimation," IEEE Trans. Ind. Appl., vol. 48, no. 1, pp. 151-160, Nov. 2012.

[9] I. Boldea, I., Paicu, G. D. Andreescu, and F. Blaabjerg, “"“Active Flux” DTFC-SVM sensorless control of IPMSM," IEEE Trans. Energy Convers., vol. 24, no. 2, pp. 314-322, May 2009.

[10] P. Giangrande, and F. Cupertino, "A simplified position observer for zero-speed sensorless control of synchronous motors," in Conf. Rec. IECON, Nov. 2009, pp. 1014-1019.

[11] A. R. Teja, C. Chakraborty, S. Maiti, and Y. Hori, "A new model reference adaptive controller for four quadrant vector controlled induction motor drives," IEEE Trans. Ind. Electron., vol. 59, no. 10, pp. 3757-3767, May 2012.

[12] Y. D. Yoon, S. K. Sul, S. Morimoto, and K. Ide, "High-bandwidth sensorless algorithm for AC machines based on square-wave-type voltage injection," IEEE Trans. Ind. Appl., vol. 47, no. 3, pp. 1361-1370, Mar. 2011.

[13] J. H. Jang, J. I. Ha, M. Ohto, K. Ide, and S. K. Sul, "Analysis of permanent-magnet machine for sensorless control based on high-frequency signal injection," IEEE Trans. Ind. Appl., vol. 40, no. 6, pp. 1595-1604, Nov. 2004

[14] S. Murakami, T. Shiota, M. Ohto, K. Ide, and M. Hisatsune, "Encoderless servo drive with adequately designed IPMSM for pulse-voltage-injection-based position detection," IEEE Trans. Ind. Appl., vol. 48, no. 6, pp. 1922-1930, Oct. 2012.

[15] K. Ide, M. Takaki, S. Morimoto, Y. Kawazoe, A. Maemura, and M. Ohto, "Saliency-based sensorless drive of an adequately designed IPM motor for robot vehicle application," in Conf. Rec. PCC, Apr. 2007, pp. 1126-1133.

[16] Y. Takase, S. Morimoto, T. Shikayama, A. Toyota, N. Umeda, and M.Koga, "Moving -Magnet Type Linear Drive System With Output Changeover of Amplifiers for Long-distance Carriage," in Conf. Rec. Jpn. IAS Annu. Conf., Aug. 2014, vol. 3, no. 65, pp. 341-344, (in Japanese).

[17] S. Makino, T. Shikayama, M. Ohto, T. Higuchi, and T. Abe, "Development of Inductor Linear Motor for High-Speed Drive," IEEJ J. Ind. Appl., vol. 135-D, no. 8, pp. 855-861, Aug. 2015, (in Japanese).

[18] S. Makino, M. Kakihara, T. Shikayama, M. Ohto, T. Higuchi, and T. Abe, "Development of Stator-Magnetless Linear Motor for Sensorless Control," in Conf. Rec. sead27, May 2015. no. 15A19, pp. 307-308, (in Japanese).

[19] S. Makino, M. Kakihara, Y. Takase, M. Takaki, T. Shikayama, M. Ohto, T. Higuchi, and T. Abe, "Development of stator-magnetless linear synchronous motor for sensorless control," in Conf. Rec. ECCE, Sep. 2016, pp. 1-7.

[20] K. Ide, K., Ha, and M. Sawamura, "A hybrid speed estimator of flux observer for induction motor drives," IEEE Trans. Ind. Electron., vol. 53, no. 1, pp. 130-137, Feb. 2006.

[21] J. T. Chen, and Z. Q. Zhu, "Coil connections and winding factors in flux-switching PM brushless AC machines," in Conf. Rec. EVER, Mar. 2009.

[22] X. Zhu, W. Hua, and M. Cheng, "Cogging torque minimization in flux-switching permanent magnet machines by tooth chamfering," in Conf. Rec. ECCE, Sep. 2016, pp. 1-7.

[23] M. Inoue, and K. Sato, "An approach to a suitable stator length for minimizing the detent force of permanent magnet linear synchronous motors," IEEE Trans. Magn., vol. 36, no. 4, pp. 1890-1893, Aug. 2000.

[24] Y. Miyamoto, M. Tanabe, T. Higuchi, and T. Abe, "Improvement of Cogging Thrust in Permanent-Magnet-Type Linear Synchronous Motors," Elect. Eng. Jpn., vol. 191, no. 1, pp. 50-58, Dec. 2015.

[25] K. C. Lim, K. Woo, G. H. Kang, J. P. Hong, and G. T. Kim, "Detent force minimization techniques in permanent magnet linear synchronous motors," IEEE Trans. Magn., vol. 38, no. 2, pp. 1157-1160, Aug. 2002.

[26] A. Souissi, I. Abdennadher, and A. Masmoudi, "An approach to reduce the cogging force in tubular linear PM synchronous machines," in Conf. Rec. EVER, Mar. 2015, pp. 1-7. 
[27] Y. Li, Y., Zhu, D. Howe, D., Bingham, and D. A. Stone, "Improved rotor-position estimation by signal injection in brushless AC motors, accounting for cross-coupling magnetic saturation," IEEE Trans. Ind. Appl., vol. 45, no. 5, pp. 1843-1850, Jul. 2009

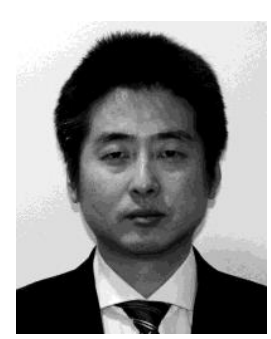

Shogo Makino received B.E. and M.E. degrees in mechanical engineering from Kyushu Institute of Technology, Kitakyushu, Japan, in 2002 and 2004, respectively.

In 2007, he joined Yaskawa Electric Corporation, Kitakyushu, Japan, where he is currently an Assistant Manager with the Motor Actuator Development Dept., Corporate R\&D Center. His current research interests include the design and development of rotary and linear motors.

Mr. Makino is a member of the Institute of Electrical Engineers of Japan.

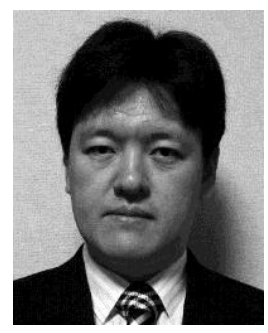

Masanobu Kakihara received B.E. and M.E. degrees in electrical engineering from Kyushu University, Fukuoka, Japan, in 2003 and 2005, respectively.

In 2005, he joined Yaskawa Electric Corporation, Kitakyushu, Japan, where he is currently a Member of the Motor Actuator Development Dept., Corporate R\&D Center. His current research interests include the design and development of servo motors and actuators.

Mr. Kakihara is a member of the Institute of Electrical Engineers of Japan.

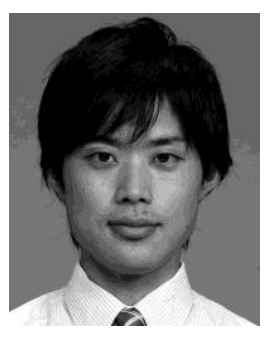

Yoshiyasu Takase received an associate's degree in mechanical engineering from Tokuyama College of Technology, Yamaguchi, Japan, in 2008.

In 2008, he joined Yaskawa Electric Corporation, Kitakyushu, Japan, where he is currently a Member of the Motion and Drive Development Dept., Corporate R\&D Center. His current research interests include high-performance motor drives and motion controls.

Mr. Takase is a member of the Institute of Electrical Engineers of Japan.

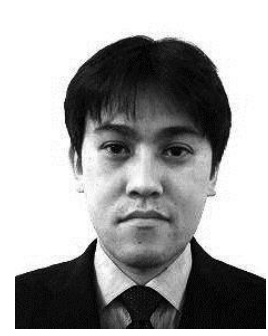

Mamoru Takaki received a B.E. degree in electrical engineering from Kyushu Institute of Technology, Kitakyushu, Japan, in 1999. In 1999, he joined Yaskawa Electric Corporation, Kitakyushu, Japan, where he is currently an Assistant Manager with the Motor Actuator Development Dept., Corporate R\&D Center. His current research interests include sensorless control and high performance motor control.

Mr. Takaki is a member of the Institute of Electrical Engineers of Japan.

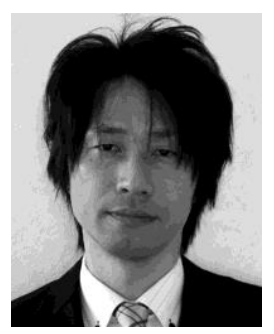

Toru Shikayama received B.E. and Ph.D. degrees in electrical engineering from Kyushu Institute of Technology, Kitakyushu, Japan, in 1993 and 2005, respectively.

In 1993, he joined Yaskawa Electric Corporation, Kitakyushu, Japan, where he is currently a Manager with the Motor Actuator Development Dept., Corporate R\&D Center. His research interests include the design and development of rotary and linear motors.

Dr. Shikayama is a member of the Institute of Electrical Engineers of Japan.

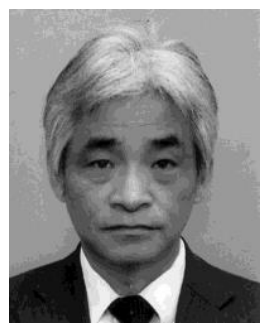

Motomichi Ohto received B.E., M.E., and Ph.D. degrees in electrical engineering from Oita University, Oita, Japan, in 1984, 1986, and 2005, respectively.

In 1986, he joined Yaskawa Electric Corporation, Kitakyushu, Japan, and he is now with Yaskawa Motor Corporation. His main research interests include technologies related to electromagnetic field analysis and electric motors.

Dr. Ohto is a member of the Institute of Electrical Engineers of Japan, and received the Third Prize Paper Award from the Electric Machine Committee of the IEEE Industry Applications Society in 2011 and the Second Best Paper Award from the Electric Machinery Committee of the IEEE Power and Energy Society in 2015.

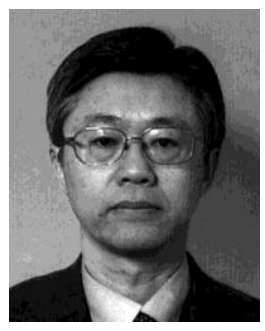

Tsuyoshi Higuchi received B.E., M.E., and Ph.D. degrees in electrical engineering from Kyushu University, Fukuoka, Japan, in 1977, 1979, and 1982, respectively.

Since 1982, he has been with the Division of Electrical Engineering and Computer Science, Nagasaki University, Japan, where he is currently a Professor. His research interests include the analysis, design, and control of linear motors and rotary motors, including induction motors, switched reluctance motors and permanent magnet motors.

Dr. Higuchi is a member of the Institute of Electrical and Electronics Engineers, the Institute of Electrical Engineers of Japan, and the Japan Society of Applied Electromagnetics and Mechanics. 


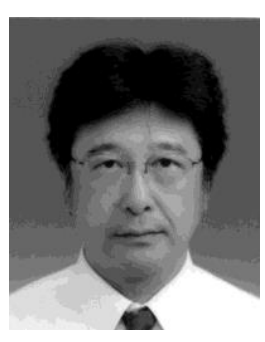

Takashi Abe received B.E., M.E., and Ph.D. degrees in electrical engineering from Nagasaki University, Nagasaki, Japan, in 1988, 1990, and 2005, respectively.

From November 1991 to July 1992, he was a Visiting Researcher at Politecnico di Torino, Italy. He is currently a Professor of Nagasaki University, Japan, Graduate

School of Engineering, the Division of Electrical Engineering and Computer Science. He has been active in the fields of electrical machine drive and power electronics.

Dr. Abe is a member of the Institute of Electrical and Electronics Engineers, the Institute of Electrical Engineers of Japan, Society of Automotive Engineers of Japan and Japanese Society for Medical and Biological Engineering. 